\title{
An Interview with P. P. Giridhar
}

MANJULAKSHI L.

P. P. Giridhar (hereafter PPG) is a distinguished linguist, a practicing translator and a translation theoretician. Eight of his English translations are available in print: Gandethimma (Macmillan India), Vaishakha (Central Sahitya Akademi), Awadheshwari (Central Sahitya Akademi), The Inscrutable Mystery (Central Sahitya Akademi), The Bounds (Partridge, USA) Life-Breath and the Truth (Partridge, USA), The Cradle (Lincom Europa, Germany), The Priceless (Lincom Europa, Germany).

Manjulakshi L. (hereafter ML) is an assistant editor of Translation Bulletin, published by National Translation Mission, interviews P. P. Giiridhar.

ML: You are basically a linguist and served in the field of Linguistics and allied subjects throughout your career. How is that you got attracted towards translation which was one of the several areas of your pursuit?

PPG: Yes, that is right. I struck out as a linguist and then forayed into fields like translation and art. Actually, I began as a literature student with the likes of URA, Vishwanath Mirle, Balagopal Verma and Rajeev Taranath as teachers at the Regional College of Education, Mysuru. It was Mirle who kindled my interest in the study of language. An add-on was my feeling that literature was not substantial enough. I recently wrote a paper published in a journal in Singapore (available online in GSTF Journal of Law and Social Sciences (JLSS) Vol.4, No. 2 October 2015) as "Art cannot Own What Reason Disowns: Caste in Kannada Literature"), ripping the much hyped piece The Death-Rite (=Sanskaara) to shreds. Literature, and art in general, has no business to dignify, legitimize, valourise and venerate an intellectual moral and 
civilizational horror like caste, which is exactly what The Death-Rite (=Sanskaara) does. Caste is man's choice-external ontology-external identity badge, one of the biggest scams in human history. I am surprised and amused that The Death-Rite (=Sanskaara) continues to be hyped and casteist literature churned out by the likes of S. L. Bhyrappa in Kannada continues to be serenaded. Even Shivaram Karant's celebrated Choma's Drum is pro-caste. This is totally unacceptable. Man needs to grow and art needs to be redefined to exclude pieces like The Death-Rite (=Sanskaara): Art needs to deepen my sense of being and bring in hope where there is none. The way The Death-Rite may be said to perform this mandate of art is fairly shallow to be sure. (Somebody has said Kuvempu is the constitution of Kannada literature. I agree.)

I had to say the above because translation as a human phenomenon is important for much the same reasons as genuine literature is important and art is important. Like art and creative literature, translation is life-giving, life-protecting, life-nourishing, life-enriching, civilization-protecting and civilization-nourishing, bridge-building, bridge-repairing, and being-deepening. Discursive translation and creative literature translation are two different footings, but they have the same broad goal of refreshing deepening, enlarging and expanding man. That is what made me gravitate to this great human act of translation. Translation tells man that while man is delightfully and colourfully diverse like a rainbow, in every one of us is the rest of mankind, something people like Walter Benjamin saw. Culturists, who harp on man's cultural diversity ad nauseam forget that cultures are but subsets of what is humanly possible, that the alleged uniqueness of individual cultures issues right out of what we all share and that the material out of which linguistic meanings are forged are hewn essentially out of the same cognitive rock which all humans are endowed with, and thus without exception, share. To exemplify, every 
human on the planet shares, and has, the material out of which the meaning of the Sanskrit word dharma has been forged so that to say that this word is not translatable is unacceptable. Such people also don't have an insider's understanding of natural language: all words including dharma are three-way constructs of the triad of an external phonetic event, an inner mind-dependent cognitive event and an external mindindependent empirical object so that to say the external phonetic event of dharma is the same as the internal cognitive event and the outer empirical event, which is what putatively makes for its alleged untranslatability, sorely and obviously, misses the point. (See my "Against Word-Monism: A Note on Ciphering out the Sound-sense Composite"), (to appear in Indian Linguistics Vol. 79 (3\&4) 2019.)

ML: What were your initial experiences when you set out with the translation of a creative work in Kannada? To what extent it was a pleasurable or a challenging experience for you?

PPG: My first experience was a creative literary work. It was at the same time pleasurable, exciting and enriching and challenging. 'Piquant' is the word. Literary translation is basically the source sensibility finding its nest in an alien soil. That is what I seek to do in every literary translational endeavor.

ML: Noted Kannada writer Srikrishna Alanahalli's Parasangada Gendethimma was probably one of the earliest literary translations you brought out. As a general reader and a translator, how did it charm you to translate into a language of a different culture? Why Alanahalli and Gendethimma only to begin with?

PPG: Yes, Alanahally's novel was my first literary translation. My own theoretical take is anything that is intelligible is translatable. It was a pleasure translating it. The only thing that went wrong with it was that the publisher wanted to make it 
smooth and glib. Smooth and glib readability has nothing to do, one can say, with the original life-blood of experience. Alanahally was a good friend and my colleague at the CIIL, Mysuru. That was one of the reasons I took it up besides of course the fact that the novel is a powerful narrative.

ML: Do Kannada idioms easily yield to be rendered into English which is culturally a different language? What were your practical experiences with respect to managing with languages during your maiden prominent take off?

PPG: My own take on translation is slightly different from the general take. Whatever is cognitively legible is translatable with provisos which also proceed from the nature of natural language. To say something is not translatable because it vectors a different culture is not exactly right. Cultural variability makes for skewness between the two linguisticcultural cosmoses. I don't quite know what 'cultural translation' as opposed to 'linguistic translation' is. Nobody does! That Kannada idioms or English idioms don't lend themselves to interlinguistic translation doesn't make sense. That the locution 'rain cats and dogs' is not translatable hardly makes sense. All idioms in any language are cognitively legible, aren't they? Certain things are not transferrable (and translatable) yes, which is what makes for the fact that the 'whole quality' of the source text is not admittedly transmitted. But to say as definitively and in as holus-bolus a manner, as people do that a translation is a 'close approximation' and the source text is 'asymptotic' is not quite right. There is also a lot of chaff going around about the translator as a curator of cultural encounters. It is said famously for example that originals get regionalised in their translations. I haven't seen a modern translation having as many avatars as there are regional versions of these translations in response to the narrativisation requirements of local ethoses, analogous to the 
much-talked about epics getting regional variants. I haven't read the several translations of One Hundred Years of Solitude but my own guess is that they all stick to the original, go by the original, subject of course to the limits and constraints of all interlinguistic translation, which one can do nothing about. Cronin has this book called Ecotranslation, but I have no idea of how all that is said there bears on actual interlinguistic translation. Maybe I am being myopic!

Given the validity of adaptation, I do not know why one should foreignise or domesticate. Given the bedrock of some basic precepts underwriting the phenomenon of translation, one needs to rigorise things like adaptation, rewriting and transcreation. We need to delimit and define adaptation studies, rewriting studies and transcreation studies. As I see it, they are not at the moment. A lot of what is not translation finds itself under the rubric of translation. For example, in the latest issue of Translation Today (Vol. 12, 1, 2018) the piece on Chemmeen has nothing substantially to do with interlinguistic translation, and yet it finds a place under TS. If one goes by the abstract the paper seeks to talk about 'how their collective memory gets translated into their day-to-day lives and rituals'.

While being possibly real, the bilingual's dissatisfaction with translations is somehow misplaced, it seems to me. To say the greatness of all great poetry is locked up in the original, which litterateurs are fond of saying, is also unjustifiably strong, or too strong, it seems to me. This militates against the undeniable truism that nothing human is alien to humans. The reality and dynamics of anything human that is really alien to humans remains to be sorted and worked out.

ML: Alanahalli and Chaduranga employ their own subtlety of local or regional Kannada language and from this point of 
view what were your experiences while translating Vaishaka as compared to Gendethimma?

PPG: I think the answer to the previous question is the answer to this question as well. The question is NOT of translating this author and that author, so that locutions like 'translating Shakespeare or translating Ananthamurthy' makes no real sense to me. One talks of translating this kind of language and that kind of language. There is no part of natural language that is exclusively one individual's preserve. Natural language is not an individual act although it originates as an individual act before it gets social through the use it is put to of communication. Natural language is a pan human act with a socially motivated lexicon: there is no room there for deeply individual idiolectal idiosyncrasies. There is on the other hand no such thing as 'poetic licence'. See Giridhar 1978 Poetic Licence: A Linguist's Eye view (Linguistics in Literature, 1978, Texas). There is this putative feeling rustic language is more difficult to translate than urban kind of language. Possibly more difficult, but not impossible. Last year i.e. in 2018 Lincom Europa in Germany published The Cradle, my English translation of the Dalit Kannada novel called Tottilu written by Mogalli Ganesh. The kind of English I forged to reflect Dalit Kannada there has been hailed as apt. See Anuradha Ghosh's review of my translation in a forthcoming issue of Translation Today. A perceived culture-internality could be the issue. I haven't ciphered this out.

ML: Avadeshwari was a cultural novel and Chidambara Rahasya had its own texture and Tejaswi's unique touch. How did you manage with the language, style and literary nuances of these works? How did you enjoy your cumulative experience and success as a translator of creative literature? 
PPG: You say Avadheshwari was a cultural novel. Is there a noncultural novel unless of course you are talking of things like scientific fiction?

Given the theoretical possibility of untranslatability (the magic of untranslatables) of some bits of natural language, translating these novels wasn't difficult. It was of course challenging. And I did a fairly successful job. Awadheshwari ran into further editions. ....

ML: To what extent do you feel that non-literary texts are being given priority these days over translation of conventional, popular, or creative literature? What do you feel about the quality of translations of non-literary or knowledge texts - individual as well as institutional - that are emerging out these days?

PPG: Literary translation and discursive translation have their own challenges. What makes discursive translation less involute and more straightforward is the quality of selfidenticality that characterizes it. It is a univocal one-way traffic, a case of dispassionate denotation.

I think both knowledge text translation and human text translation are happening in equal measure, as they indeed should. Knowledge text translation is especially empowering and enabling. It has the power of secularizing and democratising knowledge in delightfully refreshing ways. Statistically small languages must be feeling this once they see English texts in their own languages.

ML: You served as an editor of the translation journal Translation Today. Were you satisfied with the academic and research inputs of the scholars which could significantly add to the knowledge base of Translation Studies?

PPG: Yes, I was satisfied to a considerable extent. We had input from a wide variety of scholars. The only problem is in 
fact the problem of the discipline. A lot of talk in the air happens, which I critiqued in a paper I published in Meta in Canada in 2005, entitled Translatology: Interrogative Musings on the Grid.

ML: Incidentally you had the opportunity to work on Mao Naga Grammar, Angami Naga Grammar etc., and thereby get an exposure to tribal languages and culture. Do you think that the tribal cultures have got their own wealth of literature which should be translated into mainstream languages? What are your suggestions in this regard?

PPG: Every human group is special, pace the horrible supremacism that is rampant these days. Every human group, like indeed every human, is free and equal. Mainstreaming is a syndrome of this not-so-modern pathology of supremacism that is man's bane, cf the take of Sentinelese. Why should one be mainstreamed? Technology is nobody's property and none needs to be anyone's slave. A country like New Zealand has had no problems with a reported 200 ethnicities and 160 languages. I had a wonderfully rich time staying in Mao Naga villages and Angami villages in the late $70 \mathrm{~s}$ and early $80 \mathrm{~s}$. Besides writing grammars and dictionaries of these languages and subsequently publishing on their linguistic structure, I also collected some folk songs and tales, which I should have translated into English but didn't. I did publish a paper on an Angami folktale though. I also saw some wonderful dance and listened to a lot of soulful music there. I have fond memories of those days, which I will cherish to my dying day!

ML: You are endowed with an astounding experience in the field of translation - both as a translation administrator and a professional translator. Governments today are coming out with a lot of initiatives for the development of regional languages and obviously translation is an indispensable tool in this direction. A number of organizations and society in 
general are engaged in this stupendous task. What do you foresee about the status of translation in the country during the ensuing years?

PPG: Well, translation is burgeoning exponentially both as an industry, as a commercial venture and as an academic discipline. With technology helping it out in a big way it is bound to evolve into a far greater enterprise than was envisioned, say, fifty years ago. In India too it is progressing fast. With more and more people diving into the arena, and with private and state sponsorship, both knowledge translation and literary translation are bound to grow into gigantic dimensions. The prospect is really pleasantly exciting. NTM is bound to play its role in this rapidly expanding universe of knowledge translation. My good wishes!

Cite this work:

MANJULAKSHI L. (interv.). 2020. An Interview with Giiridhar P.P. Translation Today, Vol. 14(1). 101-109. DOI: 10.46623/tt/2020.14.1.in1 